\title{
Trends in preterm survival and incidence of cerebral haemorrhage 1980-9
}

\author{
R W I Cooke
}

\begin{abstract}
The annual survival rates and incidence of cerebral haemorrhage in $\mathbf{2 6 1 8}$ preterm infants of 34 weeks' gestation or less were examined in one referral centre over a 10 year period from January 1980 to December 1989. Survival was independently related to weight, gestation, sex, and inborn delivery. When these variables had been taken into account, survival was $56 \%$ greater at the end of the decade compared with 1980 . The incidence of cerebral haemorrhage (diagnosed by cranial ultrasound scanning) was related to birth weight, gestation, sex, inborn delivery, and caesarean section, but there was no significant trend in the incidence with time. Rates of caesarean section in this group increased from $31 \%$ in 1980 to over $50 \%$ more recently. Haemorrhage affecting the brain parenchyma was related to gestation and inborn delivery, and showed a small but significant decline over time. The lack of association between changes in survival rates and rates of cerebral haemorrhage may indicate that factors associated with both neonatal mortality and the incidence of cerebral haemorrhage may not be causally related as previously assumed.
\end{abstract}

There have been many reports describing improvements in survival of preterm infants over the past 20 years, and national statistics have shown a decline in birthweight specific mortality of low birthweight groups. ${ }^{1}$ Such improvements usually accompanied the introduction of intensive care techniques for low birthweight infants, rather than occurring in centres where such techniques already existed. There has been an increasing awareness of the problems associated with intracranial haemorrhage in preterm infants, and the hope was that the incidence of this potentially disabling disorder had also decreased as mortality was reduced; several reports claimed that this had occurred. ${ }^{2-4}$ This paper describes the experience of a large neonatal intensive and special care unit in the United Kingdom by examining trends in neonatal mortality and cerebral morbidity over the past decade.

Mersey Regional Neonatal Intensive Care Unit, Liverpool Maternity Hospital, Liverpool L7 7BN Correspondence to: Professor Cooke.

Accepted 16 October 1990
Patients and methods

All infants of 34 weeks' gestation or less who were admitted to the Mersey regional neonatal intensive care unit and special care unit over a 10 year period were included in the study. The variables analysed are listed in table 1 . Cranial ultrasonography has been used to diagnose cerebral lesions since late in 1979, and all infants weighing less than $1500 \mathrm{~g}$ at birth, and most larger infants receiving intensive care, were regularly examined. Data have been recorded prospectively since January 1980 to evaluate ultrasonographic diagnosis, and the data used in this paper was abstracted from this.

Ultrasound scans were not performed routinely on larger infants who were admitted only for special care, and who did not have respiratory problems or birth asphyxia. A simple grading system for cerebral haemorrhage was used to classify the early lesions: none, subependymal haemorrhage, intraventricular haemorrhage, and parenchymal haemorrhage. The last category includes both haemorrhagic infarction and venous infarction as they cannot reliably be distinguished. A more complex system of grading was not used, nor were later parenchymal lesions such as cystic periventricular leucomalacia included, because the interpretation of these lesions has been modified over the decade. Only data relating to the overall rates of haemorrhage and of parenchymal haemorrhage are reported here. Survival was defined as alive at the time of discharge from the unit. Deaths because of chromosomal and other lethal congenital abnormalities were excluded from the analysis of survival rates, but not from the other analyses.

Trends in survival and haemorrhage rates were tested using $\chi^{2}$ for trend. Univariate analysis was by the $\chi^{2}$ test or unpaired Student's $t$ test. Logistic regression was then used to test for the independent effects of the variables shown in table 1 on survival and the incidence of haemorrhage. Each year after 1980 was also entered into the logistic regressions as an independent variable to test for differences in rates of survival and haemorrhage in that year relative to the baseline of 1980 after other variables had been taken into account. The effect of categorical variables and year of birth on rates of survival and haemorrhage were then derived from the logistic regression odds ratios with their 95\% confidence intervals (CI).

The odds ratio is the change in likelihood of an event occurring if a particular variable or category of variable is present. A ratio of 1.5 indicates that the probability of occurrence is increased by $50 \%$. The odds ratio is an estimate, and the $95 \% \mathrm{CI}$ indicate the range within which 
one can be $95 \%$ certain that the true value will lie. If these limits do not encompass 1 , it is accepted that the odds ratio is significantly different from an even chance, and that a true difference exists.

\section{Results}

SURVIVAL

During the decade 1 January 1980 to 31 December 1989, 2662 infants of 34 completed weeks of gestation or less were admitted to the Mersey regional neonatal intensive care and special care unit at Liverpool Maternity Hospital. Forty four died of lethal chromosomal or other abnormalities. Of the remaining 2618 infants, 486 (18.6\%) died before discharge home. A significant trend to improved survival in more recent years was seen for all infants, for infants of less than 28 weeks' gestation, and for infants weighing less than $1500 \mathrm{~g}$ at birth (table 2). Univariate analysis also showed that survival was related to sex, gestation, birth weight, whether the infant was inborn, and whether delivery was by caesarean section (table 3). A number of these variables could have contributed to the apparent observed improvement in survival, although only caesarean section showed a significant trend related to year of birth (table 4). Logistic regression analysis showed that weight, gestational age, sex, and place of birth were independent variables that were significantly related to survival, as was year of birth. The odds ratio for survival in any one year compared with 1980 was significantly better than 1 in 1983 and from 1985 onwards when all infants were

Table 2 Percentage trends in annual survival rates in infants of 34 weeks' gestation and under, in infants of less than 28 weeks' gestation, and of infants who weighed less than $1500 \mathrm{~g}$ at birth. Figures in parentheses are numbers of infants

\begin{tabular}{llll}
\hline Year & $\begin{array}{l}\text { Infants of } \\
\leqslant 34 \text { weeks } \\
\text { gestation } \\
(\boldsymbol{n}=2618)\end{array}$ & $\begin{array}{l}\text { Infants of } \\
<28 \text { weeks } \\
\text { gestation } \\
(\boldsymbol{n}=537)\end{array}$ & $\begin{array}{l}\text { Infants who } \\
\text { weighed } \\
(\boldsymbol{n}=1470)\end{array}$ \\
\hline 1980 & $75 \cdot 1(209)$ & $41 \cdot 0(39)$ & $61 \cdot 2(121)$ \\
1981 & $77 \cdot 2(268)$ & $44 \cdot 1(59)$ & $68 \cdot 1(166)$ \\
1982 & $80 \cdot 9(278)$ & $38 \cdot 0(50)$ & $68 \cdot 8(144)$ \\
1983 & $83 \cdot 0(311)$ & $46 \cdot 0(63)$ & $75 \cdot 3(178)$ \\
1984 & $81 \cdot 3(273)$ & $38 \cdot 3(47)$ & $66 \cdot 9(142)$ \\
1985 & $81 \cdot 9(276)$ & $47 \cdot 2(53)$ & $67 \cdot 8(149)$ \\
1986 & $83 \cdot 8(277)$ & $55 \cdot 2(58)$ & $78 \cdot 8(160)$ \\
1987 & $82 \cdot 7(254)$ & $45 \cdot 6(57)$ & $72 \cdot 9(155)$ \\
1988 & $82 \cdot 9(217)$ & $64 \cdot 8(54)$ & $74 \cdot 2(124)$ \\
1989 & $84 \cdot 3(255)$ & $61 \cdot 4(57)$ & $74 \cdot 8(131)$ \\
\hline$\chi^{2}$ for trend & $8 \cdot 20$ & $10 \cdot 36$ & $7 \cdot 26$ \\
$p$ Value & 0.004 & 0.001 & 0.007 \\
\hline
\end{tabular}

Table 4 Percentage trend in the annual incidence of caesarean sections among all infants. Figures in parentheses are numbers of infants

\begin{tabular}{lll}
\hline Year & $\begin{array}{l}\text { Vaginal delivery } \\
(n=1473)\end{array}$ & $\begin{array}{l}\text { Caesarean section } \\
(n=1189)\end{array}$ \\
\hline 1980 & $69 \cdot 0(149)$ & $31 \cdot 0(67)$ \\
1981 & $61 \cdot 1(165)$ & $38 \cdot 9(105)$ \\
1982 & $61 \cdot 1(173)$ & $38 \cdot 9(110)$ \\
1983 & $59 \cdot 4(188)$ & $40 \cdot 3(127)$ \\
1984 & $48 \cdot 9(135)$ & $51 \cdot 1(141)$ \\
1985 & $52 \cdot 0(146)$ & $48 \cdot 0(135)$ \\
1986 & $43 \cdot 6(123)$ & $56 \cdot 4(159)$ \\
1987 & $57 \cdot 1(148)$ & $42 \cdot 9(111)$ \\
1988 & $55 \cdot 9(124)$ & $44 \cdot 1(98)$ \\
1989 & $47 \cdot 3(122)$ & $52 \cdot 7(136)$ \\
\hline$\chi^{2}$ for trend & \multicolumn{3}{c}{$27 \cdot 4$} \\
$p$ Value & \multicolumn{3}{c}{$0 \cdot 0001$} \\
\hline
\end{tabular}

considered (fig 1). When only infants under $1500 \mathrm{~g}$ were studied, survival was significantly better in 1983 and from 1986 onwards, and when infants of less than 28 weeks' gestation were considered, survival was significantly improved compared with 1980 only in 1988 and 1989. Caesarean section was not independently related to survival in any group, inborn delivery only to the cohort as a whole, and multiple pregnancy only to infants of less than 28 weeks' gestation.

\section{CEREBRAL HAEMORRHAGE}

Of the 2662 infants admitted, 2313 (86.9\%) had cranial ultrasound scans. All the infants who weighed less than $1500 \mathrm{~g}$ at birth or were of less than 28 weeks' gestation were scanned. When all infants were considered, the overall incidence of haemorrhage did not change over the decade (table 5). There was a small but significantly decreasing trend in the incidence of parenchymal haemorrhage (table 6). In infants weighing less than $1500 \mathrm{~g}$ at birth there was a trend towards an increasing overall incidence of all types of haemorrhage, but no change in that of parenchymal lesions. In infants of less than 28 weeks' gestation there were no significant trends in either direction. Logistic regression analysis showed that weight, gestation, caesarean section, sex, and inborn delivery were independently related to all grades of haemorrhage (table 7), and gestation and inborn deliveries were related to the incidence of parenchymal haemorrhages (table 8). After other variables had been taken into account, the incidences of both haemorrhage and parenchymal haemorrhage were higher in 1981 and 1982, and that of parenchymal haemorrhage in 1986 , 1988, and 1989, but there was no consistent

Table 3 Univariate analysis of variables relating to survival, together with odds ratios and $95 \%$ CI derived from logistic regression

\begin{tabular}{|c|c|c|c|c|}
\hline & $\begin{array}{l}\text { Infants who } \\
\text { survived } \\
(n=2132)\end{array}$ & $\begin{array}{l}\text { Infants who } \\
\text { died } \\
(n=486)\end{array}$ & p Value & Odds ratios $(95 \% \mathrm{CI})$ \\
\hline $\begin{array}{l}\text { Mean (SD) birth weight (g) } \\
\text { Mean (SD) gestation (weeks) } \\
\text { No (\%) singleton births } \\
\text { No (\%) multiple births } \\
\text { No (\%) inborn deliveries } \\
\text { No (\%) outborn deliveries } \\
\text { No (\%) vaginal deliveries } \\
\text { No (\%) caesarean sections } \\
\text { No (\%) male } \\
\text { No (\%) female }\end{array}$ & $\begin{array}{r}1546(481) \\
30 \cdot 7(2 \cdot 5) \\
1675(81 \cdot 5) \\
457(81 \cdot 2) \\
1553(84 \cdot 1) \\
579(75 \cdot 1) \\
1133(78 \cdot 0) \\
999(85 \cdot 8) \\
1165(79 \cdot 4) \\
967(84 \cdot 0)\end{array}$ & $\begin{array}{l}1035(396) \\
27 \cdot 3(2 \cdot 5) \\
380(18 \cdot 5) \\
106(18 \cdot 8) \\
294(15 \cdot 9) \\
192(24 \cdot 9) \\
320(22 \cdot 0) \\
166(14 \cdot 2) \\
302(20 \cdot 6) \\
184(16 \cdot 0)\end{array}$ & $\begin{array}{l}<0.0001 \\
<0.0001 \\
>0.05 \\
<0.0001 \\
<0.0001 \\
<0.002\end{array}$ & $\begin{array}{l}1.14(1.08 \text { to } 1.21) / 250 \mathrm{~g} \\
1.20(1.15 \text { to } 1.25) / \text { week } \\
1.01(0.88 \text { to } 1.17) \text { for multiple births } \\
1.13(1.00 \text { to } 1.28) \text { for inborn deliveries } \\
0.94(0.89 \text { to } 1.08) \text { for vaginal deliveries } \\
0.76(0.68 \text { to } 0.86) \text { for male sex }\end{array}$ \\
\hline
\end{tabular}




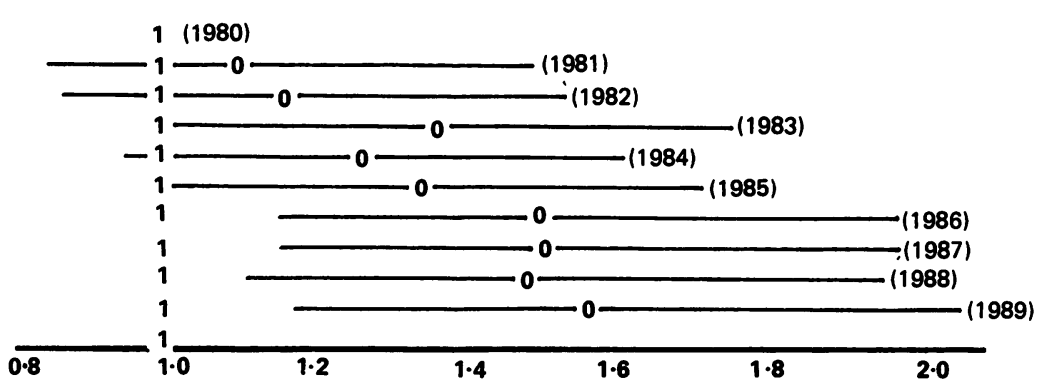

Figure 1 Odds ratio (with 95\% CI) for survival in each year compared with 1980.

Table 5 Percentage trends in annual incidence of any grade of periventricular haemorrhage in infants of 34 weeks' gestation and under, in infants of less than 28 weeks' gestation, and in infants who weighed less than $1500 \mathrm{~g}$ at birth. Figures in parentheses are numbers of infants

\begin{tabular}{|c|c|c|c|}
\hline Year & $\begin{array}{l}\text { Infants of } \\
\leqslant 34 \text { weeks } \\
\text { gestation } \\
(n=2313)\end{array}$ & $\begin{array}{l}\text { Infants of } \\
<28 \text { weeks' } \\
\text { gestation } \\
(n=546)\end{array}$ & $\begin{array}{l}\text { Infants who } \\
\text { weighed } \\
<1500 \mathrm{~g} \\
(n=1489)\end{array}$ \\
\hline $\begin{array}{l}1980 \\
1981 \\
1982 \\
1983 \\
1984 \\
1985 \\
1986 \\
1987 \\
1988 \\
1989\end{array}$ & $\begin{array}{l}39 \cdot 1(138) \\
43 \cdot 1(225) \\
41 \cdot 0(234) \\
27 \cdot 9(276) \\
32 \cdot 6(242) \\
30 \cdot 7(254) \\
50 \cdot 4(260) \\
38 \cdot 8(245) \\
40 \cdot 9(210) \\
41 \cdot 9(229)\end{array}$ & $\begin{array}{l}53 \cdot 7(41) \\
74.6(59) \\
67.3(52) \\
57 \cdot 1(63) \\
70.2(47) \\
60.4(53) \\
74.6(59) \\
70.0(60) \\
72.7(55) \\
66.6(57)\end{array}$ & $\begin{array}{l}39 \cdot 7(126) \\
53 \cdot 6(168) \\
47 \cdot 3(148) \\
37 \cdot 4(179) \\
45 \cdot 4(141) \\
43 \cdot 3(150) \\
61 \cdot 3(163) \\
49 \cdot 7(159) \\
59 \cdot 3(123) \\
55 \cdot 3(132)\end{array}$ \\
\hline $\begin{array}{l}\chi^{2} \text { for trend } \\
p \text { Value }\end{array}$ & $\begin{array}{l}1.90 \\
0 \cdot 16\end{array}$ & $\begin{array}{l}1.39 \\
0.23\end{array}$ & $\begin{array}{c}10.81 \\
0.001\end{array}$ \\
\hline
\end{tabular}

Table 6 Percentage trends in annual incidence of parenchymal haemorrhage in infants of 34 weeks' gestation and under, in infants of less than 28 weeks' gestation, and in infants who weighed less than $1500 \mathrm{~g}$ at birth. Figures in parentheses are numbers of infants

\begin{tabular}{|c|c|c|c|}
\hline Year & $\begin{array}{l}\text { Infants of } \\
\leqslant 34 \text { weeks' } \\
\text { gestation } \\
(n=2313)\end{array}$ & $\begin{array}{l}\text { Infants of } \\
<28 \text { weeks' } \\
\text { gestation } \\
(n=546)\end{array}$ & $\begin{array}{l}\text { Infants who } \\
\text { weighed } \\
<1500 \mathrm{~g} \\
(n=1489)\end{array}$ \\
\hline $\begin{array}{l}1980 \\
1981 \\
1982 \\
1983 \\
1984 \\
1985 \\
1986 \\
1987 \\
1988 \\
1989\end{array}$ & $\begin{array}{r}10 \cdot 1(138) \\
16.9(225) \\
14 \cdot 1(234) \\
8.3(276) \\
9.9(242) \\
9.4(254) \\
13.5(260) \\
6.9(245) \\
8.1(210) \\
10.5(229)\end{array}$ & $\begin{array}{r}9.8(41) \\
37.3(59) \\
34.6(52) \\
19.0(63) \\
23.4(47) \\
20.8(53) \\
33.9(59) \\
18.3(60) \\
14.5(55) \\
19.3(57)\end{array}$ & $\begin{array}{r}9 \cdot 5(126) \\
22.0(168) \\
19 \cdot 6(148) \\
11.2(179) \\
15.6(141) \\
13.3(150) \\
19.6(163) \\
10.1(159) \\
13.0(123) \\
15.9(132)\end{array}$ \\
\hline $\begin{array}{l}\chi^{2} \text { for trend } \\
\text { p Value }\end{array}$ & $\begin{array}{l}4.94 \\
0.026\end{array}$ & $\begin{array}{l}2 \cdot 10 \\
0 \cdot 147\end{array}$ & $\begin{array}{l}0.6 \\
0.43\end{array}$ \\
\hline
\end{tabular}

relationship with time. Similar results were seen for cerebral haemorrhage over time in infants weighing less than $1500 \mathrm{~g}$ at birth and of less than 28 weeks' gestation.

\section{Discussion}

Survival of preterm infants during the past decade has consistently improved. As full intensive care has been given to all infants admitted without potentially lethal malformations over this period of time, any improvment in outcome is likely to be related to changes in the population of infants treated, or to the combined effects of the many minor changes in management that have occurred. Analysis of the variables examined showed no consistent trend with time except for an increase in the proportion of caesarean sections.

When all the variables were entered into a logistic regression, caesarean section was no longer significantly associated with improved survival, although birth in more recent years was still associated with improved survival. Similar effects were noted for infants weighing less than $1500 \mathrm{~g}$ at birth, and those of less than 28 weeks' gestation, although survival was significantly better only in the most recent years. This improvement in survival is likely to be real rather than related to population changes.

The annual incidence of cerebral haemorrhage over the decade showed a different pattern. When all infants were considered, no consistent trend emerged except for a small but significant decrease in the number of parenchymal haemorrhages. Infants weighing less than $1500 \mathrm{~g}$ at birth showed an overall trend to an increased incidence of all haemorrhages, but not to parenchymal haemorrhages alone. As expected, logistic regression analysis showed correlations between haemorrhage and variables such as gestational age and weight, inborn delivery, sex, and caesarean section, but no variable was consistently correlated with the incidence of haemorrhages of different degrees or in different groupings. Similarly, some individual years showed a significantly greater incidence of haemorrhage than 1980, but no consistent trend emerged.

A number of reports have suggested that the incidence of cerebral haemorrhage among preterm infants is decreasing, but many of the observations are confined to a short period of time or to small numbers. Szymonowicz et al

Table 7 Univariate analysis of variables relating to any grade of periventricular haemorrhage, with odds ratios and $95 \%$ CI derived from logistic regression

\begin{tabular}{|c|c|c|c|c|}
\hline & $\begin{array}{l}\text { Infants without } \\
\text { periventricular } \\
\text { haemorrhage } \\
(n=1424)\end{array}$ & $\begin{array}{l}\text { Infants with } \\
\text { any grade of } \\
\text { periventricular } \\
\text { haemorrhage } \\
(n=889)\end{array}$ & p Value & Odds ratios $(95 \% \mathrm{CI})$ \\
\hline $\begin{array}{l}\text { Mean (SD) birth weight (g) } \\
\text { Mean (SD) gestation (weeks) } \\
\text { No (\%) singleton births } \\
\text { No (\%) multiple births } \\
\text { No (\%) inborn deliveries } \\
\text { No (\%) outborn deliveries } \\
\text { No (\%) vaginal deliveries } \\
\text { No (\%) caesarean sections } \\
\text { No (\%) male } \\
\text { No (\%) female }\end{array}$ & $\begin{array}{c}1492(477) \\
30 \cdot 5(2 \cdot 5) \\
1109(77 \cdot 9) \\
315(22 \cdot 1) \\
1039(73 \cdot 0) \\
385(27 \cdot 0) \\
706(49 \cdot 6) \\
718(50 \cdot 4) \\
765(53 \cdot 7) \\
659(46 \cdot 3)\end{array}$ & $\begin{array}{c}1169(402) \\
28 \cdot 2(2 \cdot 5) \\
687(77 \cdot 3) \\
202(22 \cdot 7) \\
533(60 \cdot 0) \\
356(40 \cdot 0) \\
560(62 \cdot 9) \\
329(37 \cdot 1) \\
520(58 \cdot 5) \\
369(41 \cdot 5)\end{array}$ & $\begin{array}{l}<0.0001 \\
<0.0001 \\
>0.05 \\
<0.0001 \\
<0.0001 \\
<0.02\end{array}$ & $\begin{array}{l}0.94(0.90 \text { to } 0.98) / 250 \mathrm{~g} \\
0.87(0.84 \text { to } 0.90) / \text { week } \\
1.03(0.92 \text { to } 1.16) \text { for multiple births } \\
0.78(0.71 \text { to } 0.87) \text { for inborn deliveries } \\
0.90(0.81 \text { to } 0.99) \text { for caesarean sections } \\
1.18(1.07 \text { to } 1.29) \text { for male sex }\end{array}$ \\
\hline
\end{tabular}


Table 8 Univariate analysis of variables relating to parenchymal haemorrhage, with odds ratios and $95 \%$ CI derived from logistic regression

\begin{tabular}{|c|c|c|c|c|}
\hline & $\begin{array}{l}\text { Infants without } \\
\text { parenchymal } \\
\text { haemorrhage } \\
(n=2064)\end{array}$ & $\begin{array}{l}\text { Infants with } \\
\text { parenchymal } \\
\text { haemorrhage } \\
(n=249)\end{array}$ & p Value & Odds ratios $(95 \% C I)$ \\
\hline \multirow{5}{*}{$\begin{array}{l}\text { Mean (SD) birth weight (g) } \\
\text { Mean (SD) gestation (weeks) } \\
\text { No (\%) singleton births } \\
\text { No (\%) multiple births } \\
\text { No (\%) inborn deliveries } \\
\text { No (\%) outborn deliveries } \\
\text { No (\%) vaginal deliveries } \\
\text { No (\%) caesarean sections } \\
\text { No (\%) male } \\
\text { No (\%) female }\end{array}$} & \multirow{5}{*}{$\begin{array}{c}1404(476) \\
29 \cdot 9(2 \cdot 7) \\
159(77 \cdot 3) \\
468(22 \cdot 7) \\
1438(69 \cdot 7) \\
626(30 \cdot 3) \\
1109(53 \cdot 7) \\
955(46 \cdot 3) \\
1142(55 \cdot 3) \\
922(44 \cdot 7)\end{array}$} & \multirow{5}{*}{$\begin{array}{l}1070(361) \\
27 \cdot 5(2 \cdot 3) \\
200(80 \cdot 3) \\
49(19 \cdot 7) \\
134(53 \cdot 8) \\
115(46 \cdot 2) \\
157(63 \cdot 0) \\
92(37 \cdot 0) \\
143(57 \cdot 4) \\
106(42 \cdot 6)\end{array}$} & $\begin{array}{l}<0.0001 \\
<0.0001\end{array}$ & $\begin{array}{l}0.93(0.86 \text { to } 1.003) / 250 \mathrm{~g} \\
0.87(0.83 \text { to } 0.91) / \text { week }\end{array}$ \\
\hline & & & $>0.05$ & $0.92(0.77$ to 1.11$)$ for multiple births \\
\hline & & & $<0.0001$ & $0.76(0.66$ to 0.87$)$ for inborn deliveries \\
\hline & & & $<0.006$ & $1.09(0.94$ to 1.29$)$ for caesarean sections \\
\hline & & & $>0.05$ & $1.07(0.92$ to 1.23$)$ for male sex \\
\hline
\end{tabular}

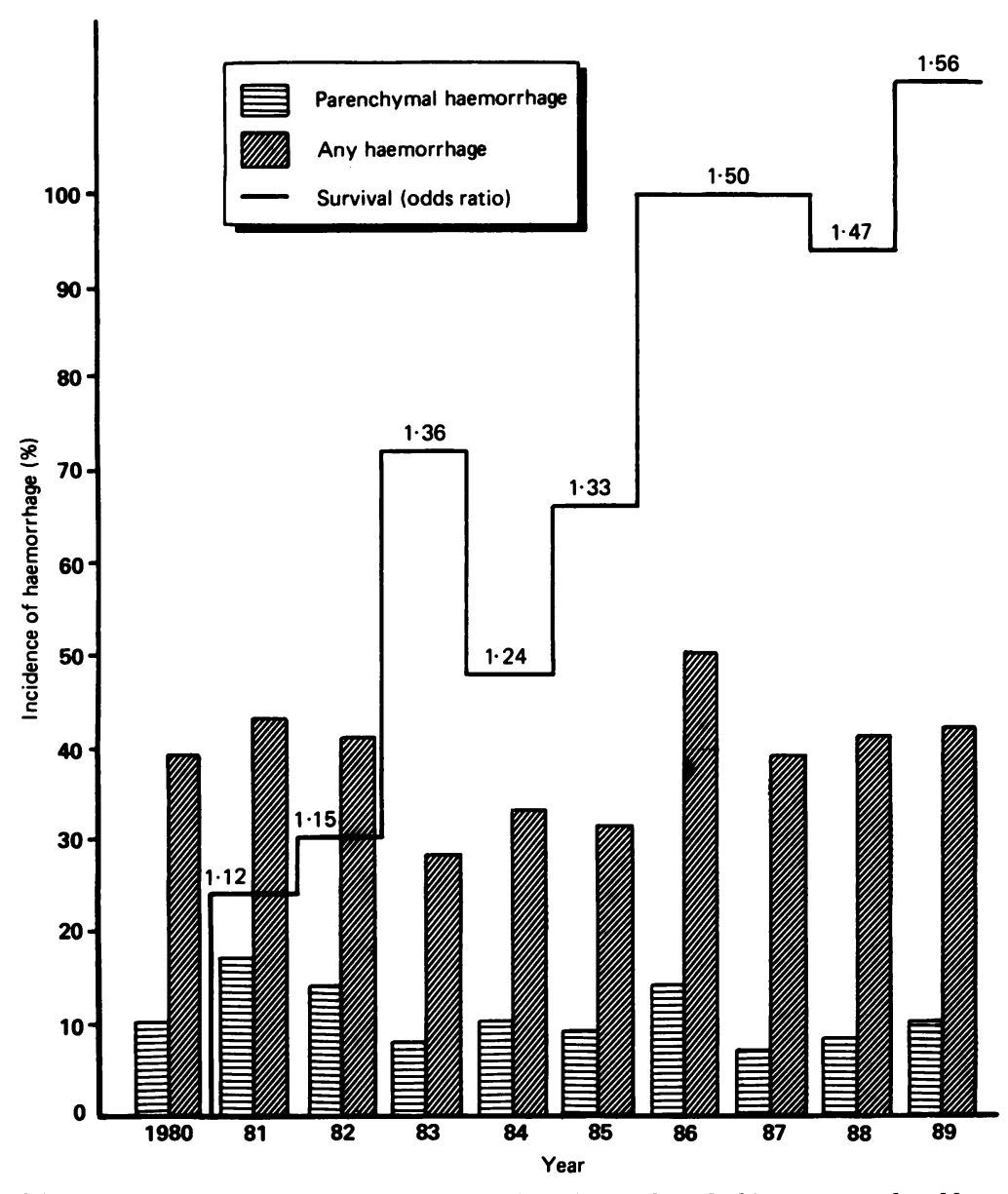

Figure 2 Incidence of haemorrhage 1980-9. Superimposed ion the histogram are the odds ratios for survival in each year compared with 1980. vival over a 10 year period seen in this study, it is somewhat surprising to note the lack of reduction in the incidence of cerebral haemorrhage (fig 2). Could other changes that we did not examine have masked a real change in the incidence of haemorrhage? The infants most intensively studied by ultrasound scanning were those weighing less than $1500 \mathrm{~g}$ at birth. Improvements in the quality of resolution of scans, and greater interest in more minor lesions in recent years, could have produced a rise in diagnoses of smaller haemorrhages over the period, so giving an overall apparent rise in incidence. The incidence of serious parenchymal haemorrhages did not alter, however, and these lesions are the least likely to be overdiagnosed.

Our policy in recent years of not admitting otherwise well infants weighing more than 2000 $g$ to the unit could have increased the apparent vulnerability of the population in the unit at the more mature end, concealing an actual fall in the incidence of haemorrhage. Factors such as a change in population in terms of weight, gestation, inborn delivery, sex, multiple births, and caesarean section were considered in the logistic regression, and did not affect the conclusions of the simpler analyses. Differences in the severity of disease may have been independent of these variables and consequently were not allowed for.

Alternatively, there may indeed have been no real change in the incidence of haemorrhage. Szymonowicz et al compared two small cohorts from two separate times. Although the change in incidence that they found was substantial, equally large changes from year to year in both directions were seen in the present study. Batton et al described a reduction in the incidence of haemorrhage in their unit from 1981 to 1983 , but a reversal of this trend in $1984 .^{4}$ The unaccounted variance in incidence from year to year means that a long term view of such changes must be taken before robust conclusions can be drawn. The use of historical controls in therapeutic intervention studies is clearly fraught with problems, and only randomised trials can hope to avoid these.

If there has been no real reduction in the incidence of haemorrhage despite improved survival, should we be surprised? It has been assumed that the antecedents of haemorrhage are largely the diseases such as hyaline membrane disease that are also related to preterm mortality. A recent commentary on hyaline membrane disease and intraventricular haemorrhage

In the light of the consistently improving sur- 
pointed out that in a meta-analysis of the results of trials of surfactant treatment of hyaline membrane disease, the mortality and severity were considerably reduced, though there was no significant effect on the incidence of cerebral haemorrhage. ${ }^{5}$ Although a few trials showed a reduction in the incidence of haemorrhage, this was no more than might have been expected by chance. Such findings call into question the relationship between diseases such as hyaline membrane disease and intraventricular haemorrhage, and whether it is causal or merely simple association. Furthermore, the reduction in perinatal mortality in low birthweight infants during the past 20 years has been accompanied by an increase rather than a decrease in later morbidities such as cerebral palsy. ${ }^{6}$

Though a number of therapeutic interventions have been shown in randomised trials to reduce haemorrhage in selected subgroups, their effect on the whole population over the last decade has not been obvious, despite a con- tinued improvement in survival. ${ }^{7}$ The causes of cerebral haemorrhage in preterm infants may not be as closely related to perinatal factors as previously thought.

1 Pharoah POD, Alberman E. Annual statistical review. Arch Dis Child 1988;63:1511-5.

2 Szymonowicz W, Yu VYH, Walker A, Wilson F. Reduction in periventricular haemorrhage in preterm infants. Arch $D$ is Child 1986;61:661-5.

3 Philip AGS, Allan WC, Tito AM, Wheeler LR. Intraventricular hemorrhage in preterm infants: declining incidence in the 1980s. Pediatrics 1989;84:797-801.

4 Batton DG, De Witte DB, Boal D, Nardis EE, Maisels MJ Incidence and severity of intraventricular hemorrhage: 1981-1984. Am J Perinatol 1986;3:353-6.

5 Leviton A, VanMarter L, Kuban KCK. Respiratory distress syndrome and intracranial hemorrhage: cause or associa-
tion? Inferences from surfactant clinical trials. Pediatrics 1989;84:915-22.

6 Pharoah POD, Cooke T, Cooke RWI, Rosenbloom L. Birthweight specific trends in cerebral palsy. Arch Dis Child 1990;65:602-6.

7 Cooke RWI. The prevention and management of germinal layer hemorrhage and intraventricular hemorrhage. In: Pape KE, Wigglesworth JS, eds. Perinatal brain lesions: contemporary issues in fetal
Blackwell, 1989:191-217. 